\title{
A STUDY OF THE EFFECT OF AN ANION EXCHANGE RESIN ON GASTRIC AND DUODENAL SECRETIONS AND GASTRIC EMPTYING ${ }^{2}$
}

\author{
By C. WILMER WIRTS AND MARTIN E. REHFUSS, WITH THE TECHNICAL ASSISTANCE OP \\ B. A. DELSERONE AND BEATRICE WASS \\ (From the Department of Medicine and the Gastrointestinal Clinic, Jefferson Medical College \\ and Hospital, Philadelphia)
}

(Received for publication July 25, 1949)

The use of synthetic resins as exchange adsorbents which would take up hydrochloric acid was first described by Adams and Holmes (1) in 1935. In 1945 Segal (2) and his associates used a polyamine-formaldehyde resin (Amberlite IR-4) as an anion exchange resin on the gastric secretions of rats. The acid neutralizing characteristics of the resin suggested its trial in the treatment of peptic ulcer but the large volume required to remove clinical amounts of acid from solution rendered its use impractical, even though feeding experiments showed the substance to be innocuous. However, in 1946 Martin and Wilkinson (3) overcame this difficulty. They showed that Amberlite IR -4 was an effective acid neutralizer in amounts practical for clinical use if a fine mesh was used. In contrast to the 40 mesh of Segal et al., a finer mesh of 200 permitted a greater surface area to be exposed for adsorption of acid. Martin and Wilkinson (3) also compared this resin to other antacids and felt that it had the following advantages: 1 . quicker action; 2 . greater neutralizing power when used in sufficiently large doses; 3. complete inhibition of peptic activity; 4 . no phosphate ion removal; 5 . no acid rebound; 6 . no constipating effect; 7 . no chloride removal.

With the exception of those reports (4-8) dealing with the use of this resin in the treatment of peptic ulcer patients, all the available data dealing with Amberlite IR-4 have been obtained from in vitro or animal experimentation. It was thought, therefore, that it would be of interest to study the effect of this resin on gastric and duodenal acidity, peptic and tryptic activity and gastric emptying in vivo in both normal subjects and in patients with peptic ulcer. The present study deals only with the effect of the resin on gastric and duodenal acidity, pepsin, and gastric empty-

1 This study was made possible by a grant from The National Drug Company, Philadelphia, $\mathbf{P a}$. ing time. Other phases of this problem will form the basis of a subsequent report.

To assay the effect of this resin on the intestinal tract we have attempted to create experimental conditions which would simulate as closely as possible the most difficult conditions under which it might be used clinically. This to our minds is represented by an ulcer patient whose stomach is empty but contains a large volume of gastric juice of high acidity and peptic activity. We did not consider that a test meal in the stomach would produce these conditions since it did not permit observation of gastric juice of high acid and pepsin content. Babkin (9) feels that histamine and insulin gastric tests offer the nearest approach to conditions of physiological experiment. Our studies showed a greater secretion of pepsin after insulin stimulation in both ulcer and non-ulcer subjects, but the acid secretion was variable. While the acid titre was higher in many patients following histamine stimulation when compared to insulin, this was not sufficiently consistent to be reflected in our average curves. We confirmed the findings of Rivers et al. (10) who demonstrated a continued rise in acidity without a proportionate rise in pepsin following a second dose of histamine in ulcer patients. Babkin and his colleagues describe this finding as a "washing out" process. Therefore, to provide the highest concentration of acid and pepsin in the gastric juice it appeared desirable to employ both histamine (repeated dose) and insulin stimulation.

\section{MATERIAL AND METHODS}

Three different methods were employed for testing the effect of the resin on gastric acidity and peptic activity: 1. following hypodermic injection of histamine; 2 . following the intravenous administration of insulin; and 3. without stimulation of the gastric secretion. In this way it was felt that the effect of the resin could be observed when there was 1. maximum stimulation of gastric acid- 
ity ; 2. maximum stimulation of peptic activity; and 3. rebound effect.

\section{Histamine stimulation}

Twenty-one non-ulcer bearing subjects and 20 patients with peptic ulcer (18 had duodenal and two gastric ulcer), attending the gastrointestinal clinic of Jefferson Hospital, were tested. The patients came to the clinic in the morning without breakfast. After aspiration of the fasting residuum, the first of two doses of histamine phosphate $0.55 \mathrm{mg}$. was given intramuscularly. Specimens of gastric juice were taken every 30 minutes thereafter for one hour. At the end of the first hour a second injection of histamine was given in the same dosage and two more samples of gastric juice were collected at 30 minute intervals. The free and total acidity of the gastric specimens were titrated, employing Toepfer's solution and phenolphthalein, while the peptic activity was determined according to the method of Riggs and Stadie as modified by Friedman (11). After establishing an average curve for the concentration of acid and pepsin by this method in both the ulcer and non-ulcer patients the technique was modified as follows: Each patient had three additional tests performed on different days, taking orally, at the beginning of the second hour $3.2 \mathrm{Gm}$. resin in $50 \mathrm{cc}$. water, or $0.6 \mathrm{Gm}$. of aluminum hydroxide, or $0.6 \mathrm{Gm}$. of a modified Sippy powder. The latter contained sodium bicarbonate one part, bismuth subcarbonate one part and calcium carbonate two parts. The dosage ratio of the resin and aluminum hydroxide was based on the in vitro findings which showed that a one to five ratio had approximately comparable neutralizing power. The quantity of the modified Sippy powder was selected for convenience and because it approximated the dosage we have employed therapeutically in the gastrointestinal clinic.

\section{Duodenal effect}

If acid and pepsin play a role in the production or aggravation of peptic ulcer it would appear important to study the effect of antacid therapy in the area in which the ulcer occurs. Therefore, ten ulcer subjects, and ten non-ulcer subjects were studied by introducing a modified Wallace-Diamond tube into the stomach and duodenum which permitted the simultaneous aspiration of secretion from the stomach and from the first portion of the duodenum. This tube was anchored in position so that its distal end was in the third portion of the duodenum and a small rubber bag containing mercury, attached to the end of the tube by a $3.0 \mathrm{~cm}$. length of string, hung over the angulation at the ligament of Treitz. The tube was checked as to position several times under the fluoroscope. When the tube was properly positioned the patient was placed on his right side or back, whichever permitted obtaining the specimens more readily, and suction pressure of $50 \mathrm{~mm}$. mercury was applied simultaneously to both tubes by means of a water pump. After obtaining fasting gastric and duodenal samples $0.55 \mathrm{mg}$. of histamine phosphate was given hypodermically and samples of secretions from both zones were obtained every 30 minutes for two hours. At the beginning of the second hour a second dose of $0.55 \mathrm{mg}$. histamine phosphate was given and immediately thereafter the patient drank $3.2 \mathrm{Gm}$. of resin in $50 \mathrm{cc}$. water. The secretions from both tubes were titrated for free and total acid and the peptic activity was determined by the method previously mentioned. The $\mathrm{pH}$ of each specimen also was determined by means of a Leeds-Northrup $\mathrm{pH}$ indicator which uses a glass electrode.

\section{Insulin stimulation}

An additional group of 15 normal subjects and 15 ulcer patients were tested for their gastric secretory response to insulin. These patients presented themselves fasting and after the gastric residuum was extracted, crystallin insulin, 0.1 unit per kilo of body weight, was given intravenously. Blood sugars were taken routinely 40 to

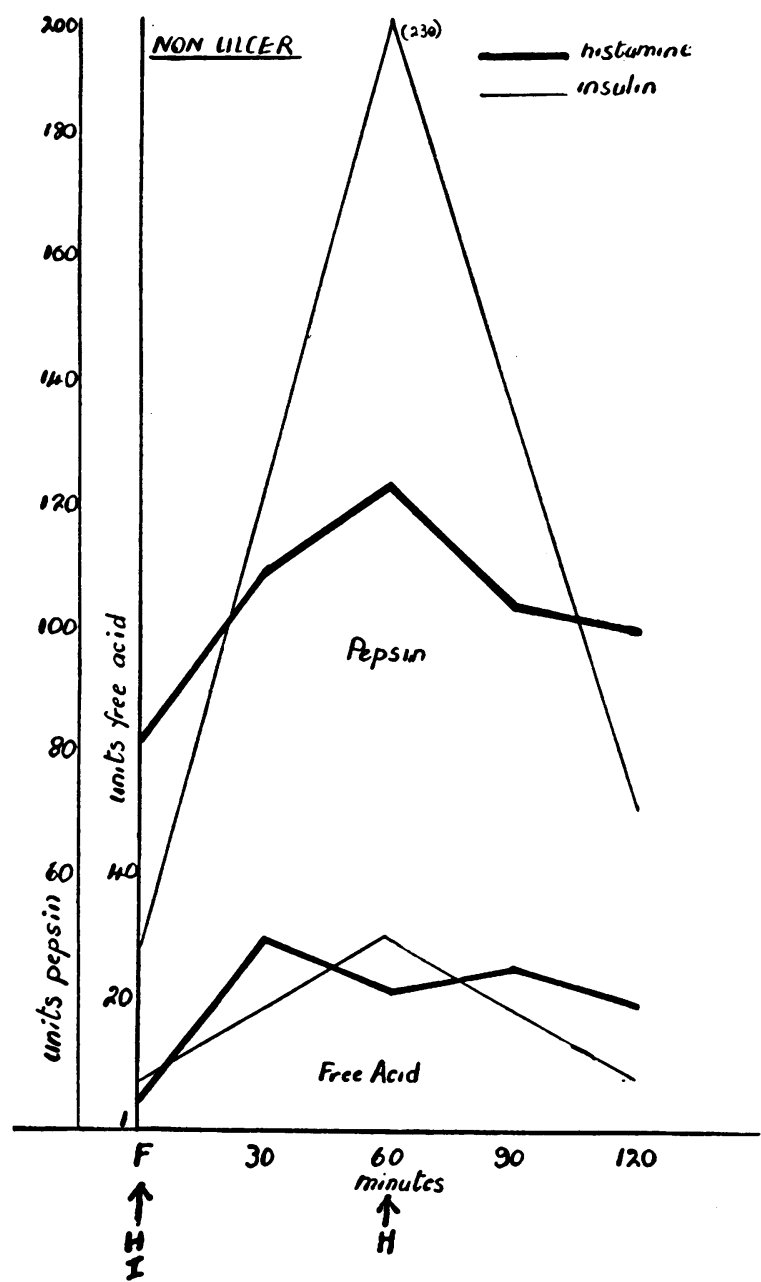

Fig. 1. Average Free Acid and Pepsin Curves Comparing Histamine (Repeated Dose) and Insulin Stimulation in Non-Ulcer Patients

$H$ represents histamine administration and $I$ represents insulin administration. 
60 minutes following insulin administration to determine the degree of hypoglycemia. After the average concentration curves for gastric acidity and pepsin were established for the normal subjects and the ulcer patients, each patient had the test repeated three times, taking orally the resin, the aluminum hydroxide and the Sippy powder in the same dosage used in the histamine tests. The antacid was given immediately after the injection of insulin and samples of the gastric juice were removed at one and two hour intervals only, because of the small volume frequently present.

\section{Rebound}

Five normal subjects and eight with duodenal ulcer were selected for an evaluation of rebound of the gastric acidity following use of the resin. After the fasting residuum was removed the patient was given $1.0 \mathrm{Gm}$. of sodium bicarbonate in $50 \mathrm{cc}$. of water, and a sample of the gastric juice for titration of acid and pepsin determination was removed every 30 minutes for two hours. Nothing in the way of a meal or gastric stimulant was administered. This procedure was then repeated on the same patient on different days using first $3.2 \mathrm{Gm}$. of resin, then $0.6 \mathrm{Gm}$. of aluminum hydroxide in place of the sodium bicarbonate.

\section{Emptying time}

Because of the difficulty encountered with insoluble materials blocking the stomach tube, it was decided to use fluoroscopic observation to determine gastric emptying time when the resin was ingested with a test meal. Thirty-eight subjects were studied; 16 were normal and 22 had peptic ulcer (20 duodenal and two gastric ulcer). The test meal consisted of $15 \mathrm{Gm}$. cooked oatmeal and $100 \mathrm{Gm}$. barium sulfate made up to $200 \mathrm{cc}$. with water. The meal was taken in the fasting state and food, fluids or smoking were not allowed during the observation period. Serial fluoroscopic examinations were made with the subject in the erect position. The outline and position of the stomach was traced on translucent paper immediately after taking the meal and at 15 and 30 minute intervals thereafter until the stomach was empty. Each patient had the test repeated on different days, once with $3.2 \mathrm{Gm}$. of resin added to the above test meal and once with $0.6 \mathrm{Gm}$. aluminum hydroxide.

\section{RESULTS}

The results of this study have been converted to average figures and are readily observed by reference to the charts. It will be noted in Figures 1 and 2, which represent a comparison of control groups in whom gastric secretion was stimulated by histamine and insulin, that the former produces an average acid titre comparable to insulin, while the latter produces the highest pepsin activity. Also, as found by Rivers et al. (10) gastric acidity is higher during the second hour, after

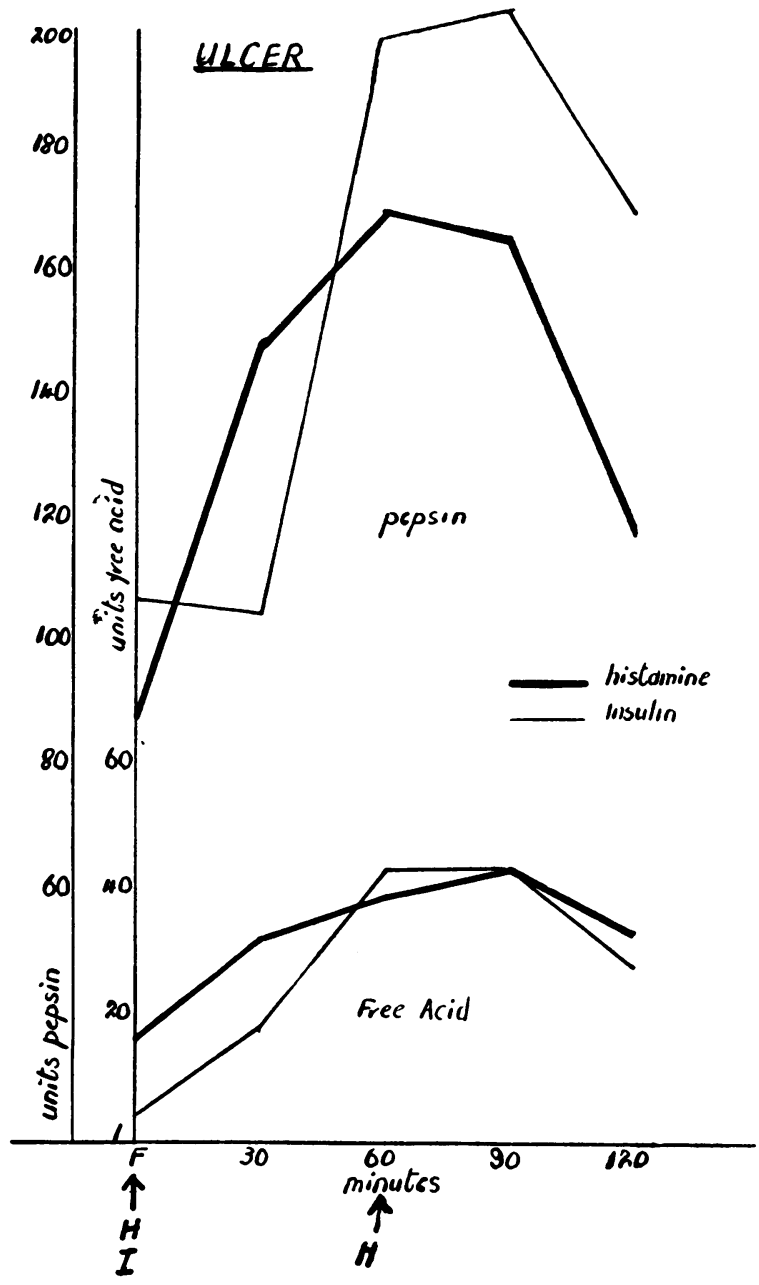

Fig. 2. Average Free Acid and Pepsin Curves Comparing Histamine (Repeated Dose) and Insulin, Stimulation in Ulcer Patients

$\mathrm{H}$ represents histamine administration and $\mathrm{I}$ represents insulin administration.

the second dose of histamine, in ulcer patients but not in non-ulcer patients. Peptic activity appears to parallel acid titre in both groups following both types of stimuli; it is higher following insulin than histamine. These curves form a base line for all the subsequent tests, but since there is such variability in acid and pepsin response to different stimuli in different patients, as well as in individual response at different times, the first hour of the histamine test and the plain insulin test may be used as separate controls. Figure 3 represents the average acid and pepsin curves in non-ulcer patients following histamine and the taking of one of the antacids at the beginning of 


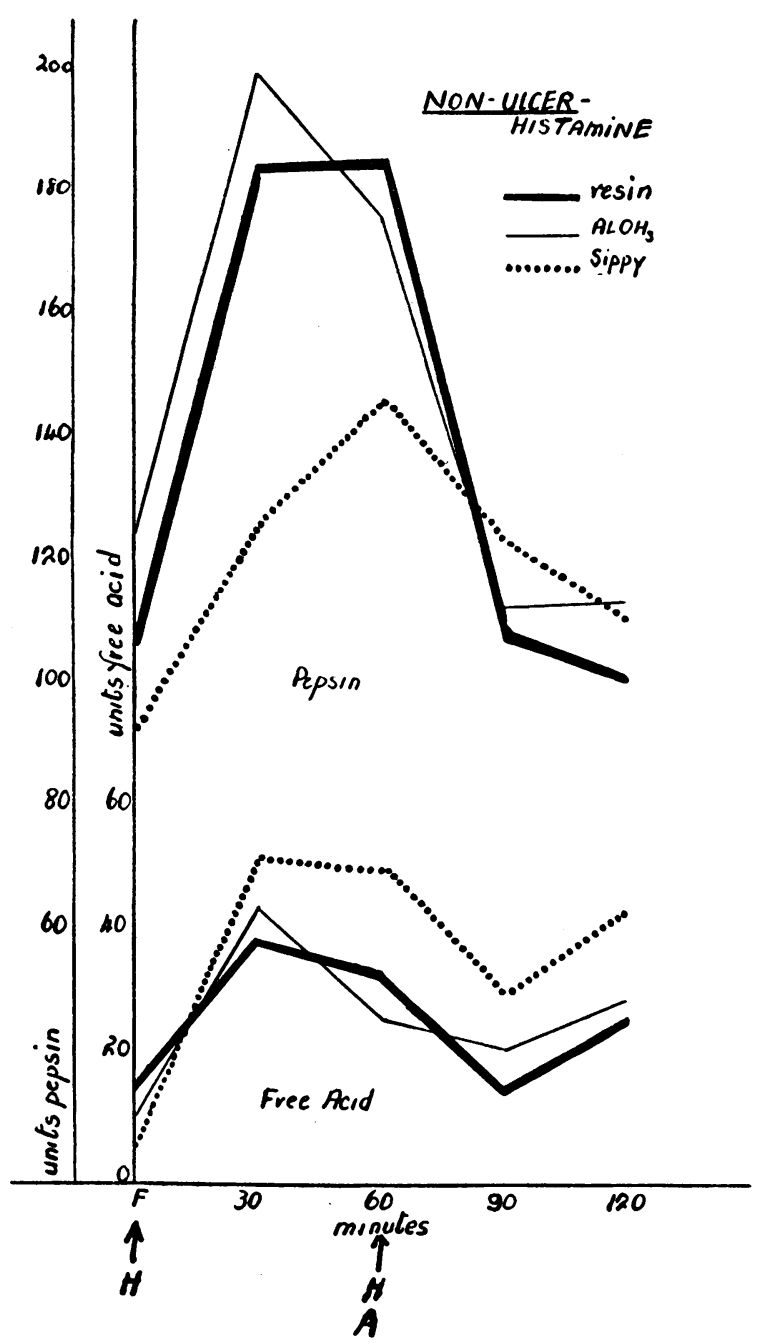

Fig. 3. Average Free Acid and Pepsin Curves Following Histamine Stimulation (Repeated Dose), Comparing the Effect of Antacids During the Second Hour in Non-Ulcer Patients

$\mathrm{H}$ represents histamine administration and $\mathrm{A}$ represents antacid administration.

the second hour. The resin and the aluminum hydroxide have a comparable effect in neutralizing acid and inhibiting pepsin. While both appear to have a more pronounced effect than the modified Sippy powder, the curves during the first hour should be noted. The fact that the free acid rises higher during the first hour in the group of patients receiving Sippy powder than in the other two groups, and the disproportionate rise of pepsin is another example of the variability of response to gastric stimulus. This demonstrates the importance of regular controls. Figure 4 shows similar results in the ulcer patients. While there is a relative difference in the reduction of acid in the second hour, a difference in the acid rise is also noted in the first hour. Figure 5 shows the unmodified acid-pepsin response to insulin stimulation in a group of non-ulcer subjects compared to the response when an antacid is given and Figure 6 shows the results in ulcer patients. While there is a difference in the acid reduction obtained by these three antacids in both groups of patients, it is of insufficient magnitude and too inconstant to consider the effect specific. In Fig-

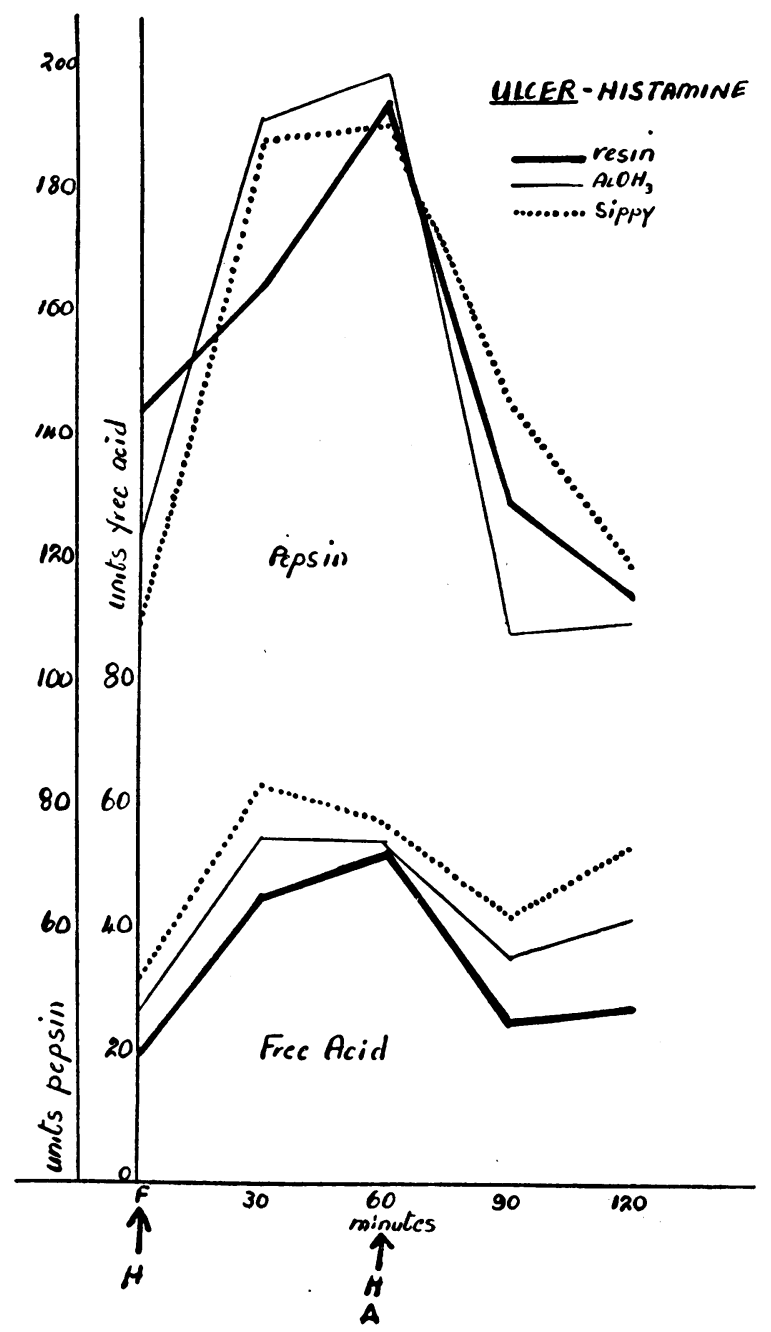

Fig. 4. Average Free Acid and Pepsin Curves Following Histamine Stimulation (Repeated Dose), Comparing the Effect of Antacids During the Second Hour in Ulcer Patients

$H$ represents histamine administration and $A$ represents antacid administration. 
ure 5 the resin produces the lowest acid curve, while in Figure 6 this is produced by aluminum hydroxide. Again in Figure 6 the Sippy powder causes a disproportionate fall in pepsin with a relatively high acid curve.

When simultaneous samples of gastric and duodenal juice were obtained following histamine stimulation (repeated dose) they were tested for $\mathrm{pH}$, free acid and pepsin; Figure 7 compares the average values in a group of non-ulcer subjects. While free acid is shown to be present in the duodenum during the fasting state, this was

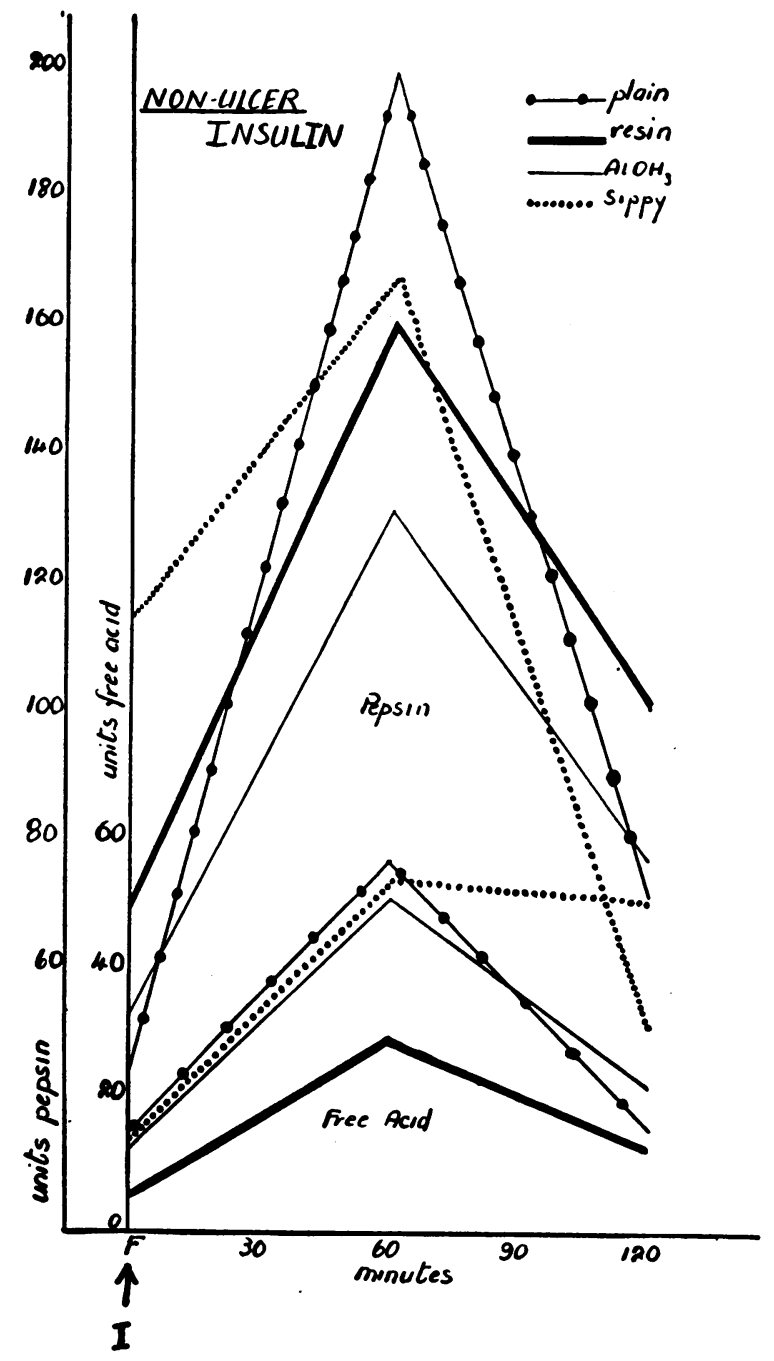

Fig. 5. Average Free Acid and Pepsin Curves Comparing the Effect of Insulin Stimulation with Antacids (Resin, Aluminum Hydroxide and Sippy) and Without (Plain) in Non-Ulcer Patients

I represents insulin administration.

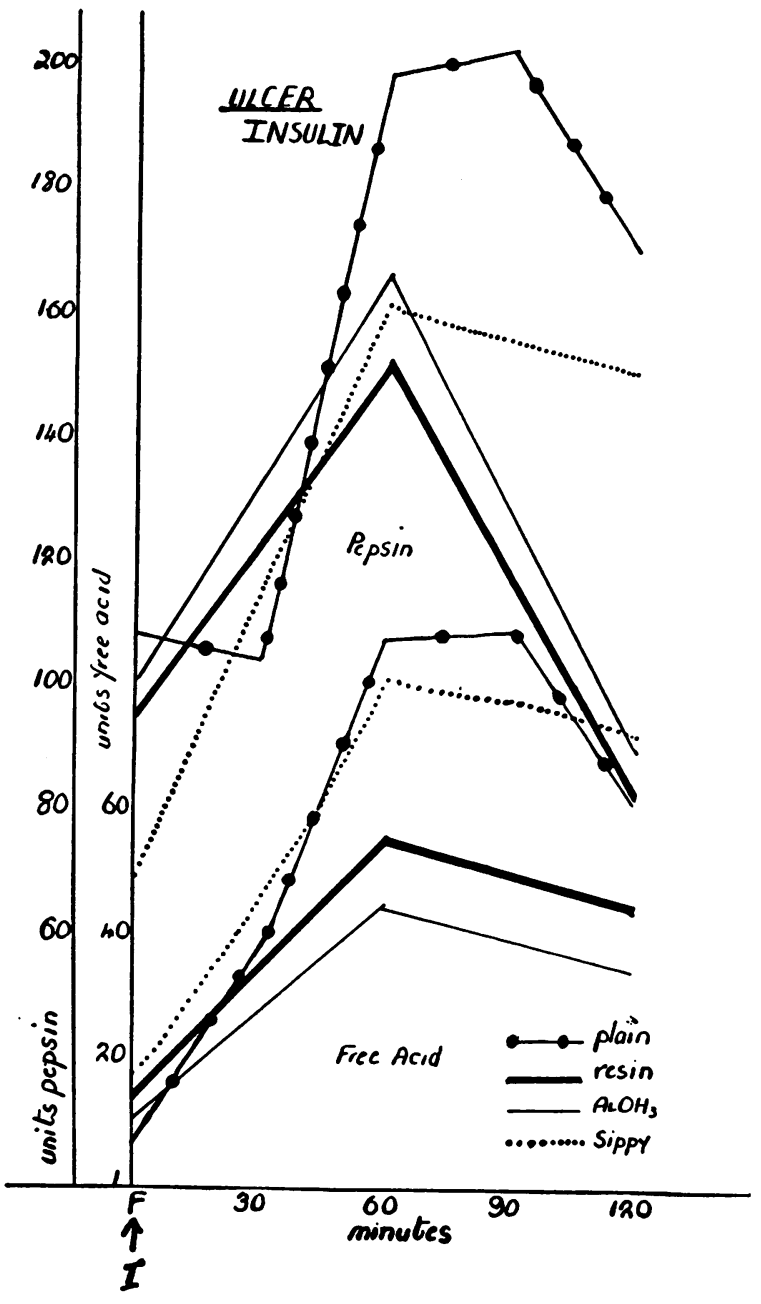

Fig. 6. Average Free Acid and Pepsin Curves Comparing the Effect of Insulin Stimulation with ANTacids (Resin, Aluminum Hydroxide and Sippy) and Without (Plain) in Ulcer Patients

I represents insulin administration.

only true in four of the ten subjects. The $\mathrm{pH}$ was 3.5 or lower in five subjects, but the average figure was 5.5. Pepsin was not present in the duodenum in the absence of free acid, but was present in each subject in whom free acid was demonstrated. Three subjects had very high acid and pepsin values in the gastric juice, which accounts for the disproportionate average pepsin curve. It is felt that this would have been lower if a larger series of patients were studied. After histamine stimulation there was a rise in the free acid and pepsin in the duodenum, but only occasionally was this proportionate to the rise in the gastric juice. In 


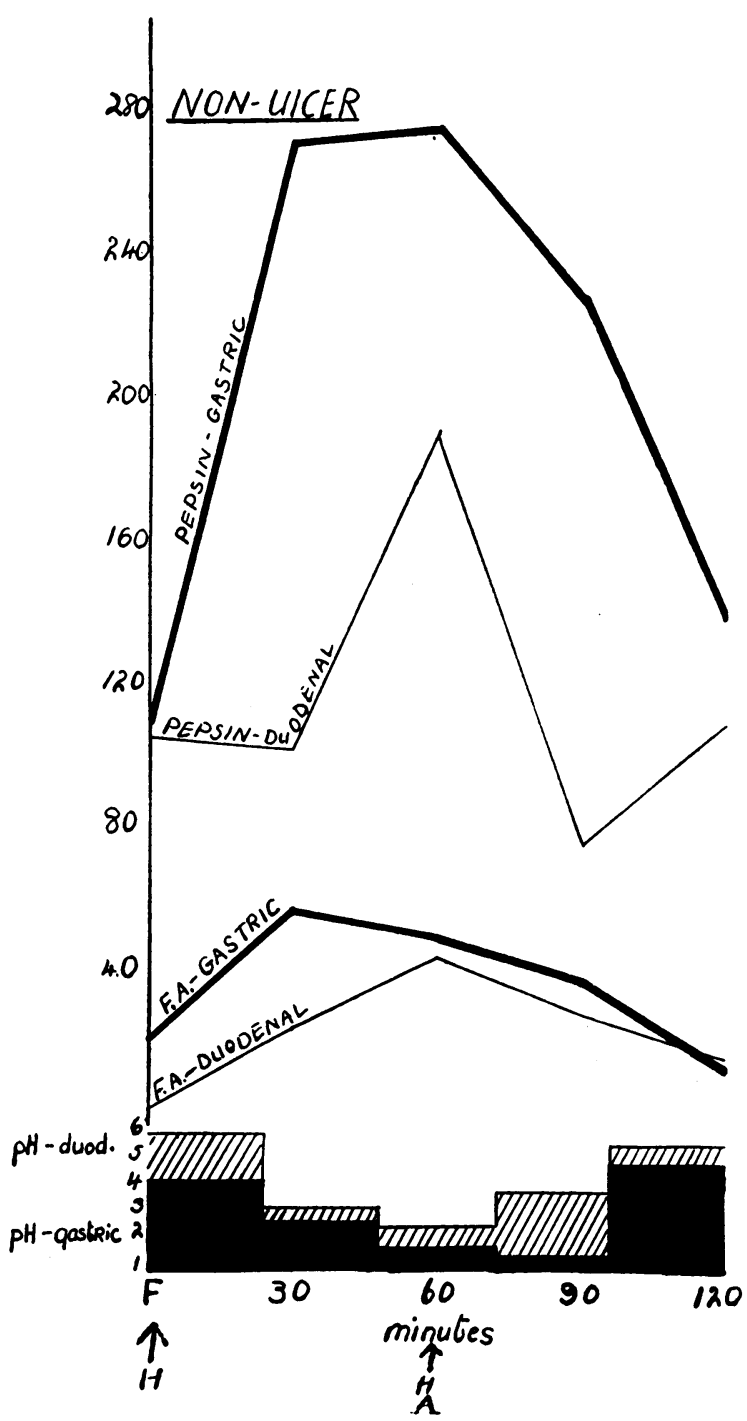

Fig. 7. Average Free Acid, Pepsin and pH Values Found in Gastric and Duodenal Juice Obtained Simultaneously in Non-Ulcer Subjects

Histamine $\mathrm{H}$ stimulation was given after the fasting contents were removed and again at 60 minutes. The resin $\mathrm{A}$ was also given at 60 minutes.

the majority of patients it was demonstrated in the 60 minute sample rather than the 30 . After the resin and second histamine injection were given at the beginning of the second hour, the free acid and pepsin values in the duodenum fell and the $\mathrm{pH}$ rose. At the 90 minute interval five subjects showed free acid, while at 120 minutes free acid was present in only three patients.

Figure 8 shows the average values for $\mathrm{pH}$, free acid and pepsin in the gastric and duodenal secre- tion with the double lumened tube in a group of ulcer patients. While the average fasting $\mathrm{pH}$ values were somewhat lower than in the non-ulcer groups (4.5 compared to 5.5 ) a similar difference was not demonstrated in the free acid determined colorimetrically. Again (as in the non-ulcer group), the levels of free acid and pepsin in the duodenum did not rise in proportion to that in the stomach, nor did the $\mathrm{pH}$ fall proportionately. After the administration of the resin there was a substantial drop in the free acid and pepsin both in the stomach and duodenum and there was a rise in the $\mathrm{pH}$ values.

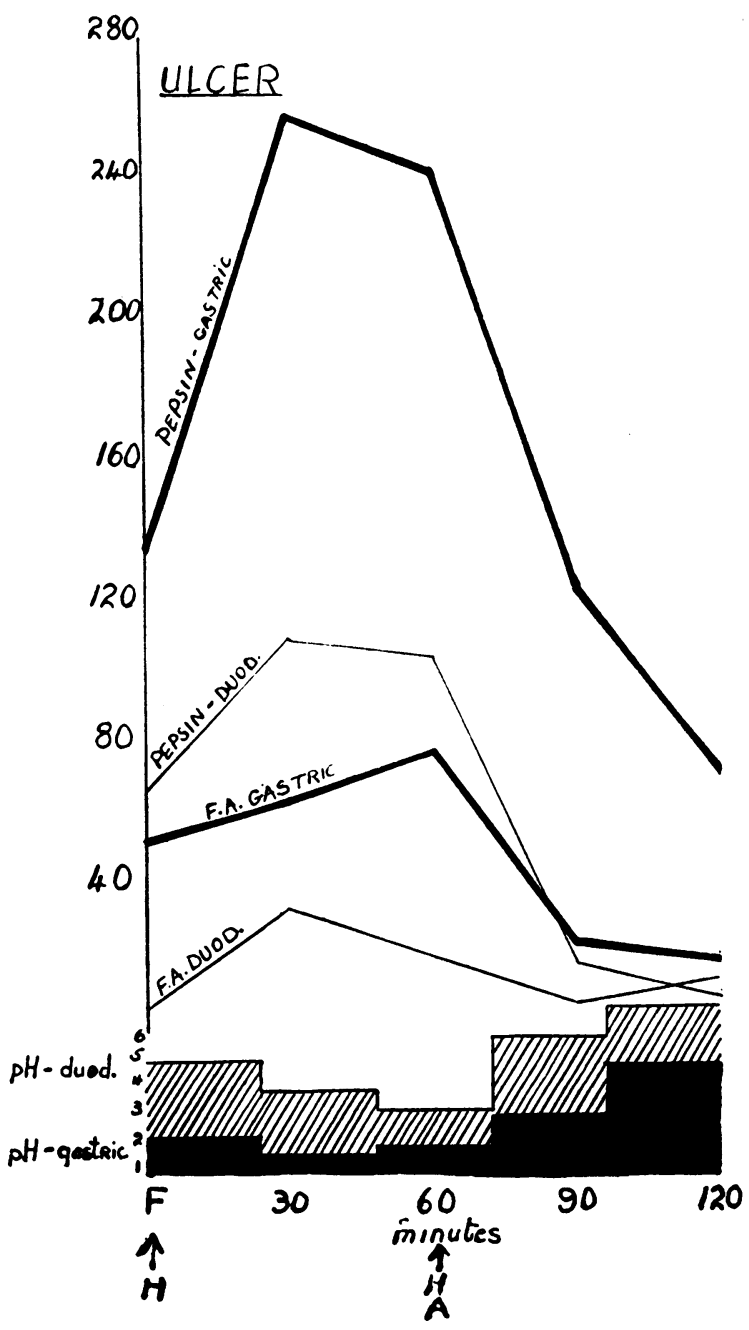

Fig. 8. Average Free Acm, Pepsin and pH Values Found in Gastric and Duodenal Juice Obtained Simultaneously in Ulcer Subjects

Histamine $\mathrm{H}$ stimulation was given after the fasting contents were removed and again at 60 minutes. The resin $\mathrm{A}$ was also given at 60 minutes. 
In Figure 9 a comparison is shown of the average values for free acid in 14 patients (eight ulcer and six non-ulcer) when sodium bicarbonate, resin and aluminum hydroxide are administered separately and without stimulation of the gastric secretion. The purpose of this study was to determine the presence of rebound in gastric acidity which has been claimed by some to follow the use of absorbable alkalies. The average figures show that an acidity higher than the fasting can develop 75 to 90 minutes following the administration of sodium bicarbonate and the development of an initial complete neutralization. However, in some patients partial neutralization of free acid would persist for two and three hours without rebound. The effect of the resin and aluminum hydroxide was comparable and the average figures show partial reduction in free acid without rebound.

Table I shows the results of the porridge-barium emptying times in ulcer and non-ulcer subjects and a comparison of the plain meal with ones to which $3.2 \mathrm{Gm}$. of resin or $0.6 \mathrm{Gm}$. of aluminum hydroxide have been added.

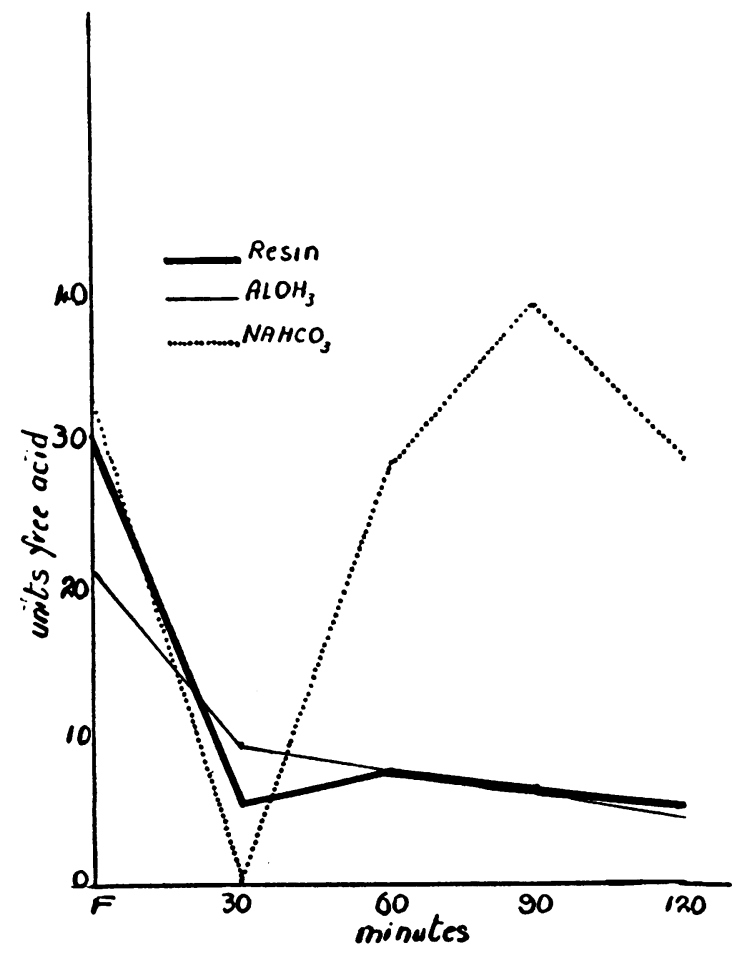

Fig. 9. Average Curves of Free Acid Comparing the Effect of Antacids Without Gastric Stimulation

The antacids were given immediately after the fasting samples were taken.
TABLE I

\begin{tabular}{|c|c|c|c|c|}
\hline Lesion & $\begin{array}{l}\text { Number of } \\
\text { subjects }\end{array}$ & $\begin{array}{l}\text { Plain } \\
\text { meal }\end{array}$ & $\begin{array}{l}\text { Resin } \\
\text { added }\end{array}$ & $\begin{array}{c}\mathrm{Al}\left(\mathrm{OH}_{3}\right) \\
\text { added }\end{array}$ \\
\hline $\begin{array}{l}\text { Duodenal ulcer } \\
\text { Gastric ulcer } \\
\text { Non-ulcer }\end{array}$ & $\begin{array}{c}\text { minutes } \\
20 \\
2 \\
16\end{array}$ & $\begin{array}{c}\text { minutes } \\
116 \\
62 \\
109\end{array}$ & $\begin{array}{c}\text { minutes } \\
108 \\
80 \\
108\end{array}$ & $\begin{array}{c}\text { minutes } \\
101 \\
75 \\
105\end{array}$ \\
\hline Total & 38 & & & \\
\hline
\end{tabular}

This table shows there is no significant difference in the gastric emptying time of duodenal ulcer and non-ulcer subjects when the plain meal is taken or when the resin or aluminum hydroxide is added. However, the emptying time of the gastric ulcer patient is much more rapid than the normal or duodenal ulcer patient when the plain meal is taken, and it is somewhat prolonged when the resin or aluminum hydroxide is added. Since there were only two patients in the gastric ulcer group it is doubtful if much significance should be attached to these figures. It is quite evident that neither the resin nor the aluminum hydroxide had any effect on gastric emptying time in normal subjects or duodenal ulcer patients. If the results on the gastric ulcer patients are to be considered significant then the effect of the resin and the aluminum hydroxide are comparable.

By dividing the group of 38 patients studied according to the shape or outline of the stomach, 18 were found to be steer-horn and $20 \mathrm{~J}$-shaped. Of the 18 steer-horn type, 11 were males and seven females; nine had duodenal ulcer and one gastric ulcer; eight were free of ulcer. The average age of this group was 51.5 years and the average gastric emptying time was one hour and 37 minutes. Of the $20 \mathrm{~J}$-shaped, 13 were males and seven females; 11 had duodenal ulcer and one gastric ulcer; eight were free of ulcer. The average age was 47.7 years and the average emptying time one hour and 43 minutes. Therefore, neither the sex, age, shape of stomach nor presence or absence of ulcer (with the possible exception of the gastric ulcer) had a demonstrable effect upon the gastric emptying time in this group of patients. Also, neither the resin nor aluminum hydroxide had any significant effect on gastric emptying when evaluated in relation to these different factors. 


\section{DISCUSSION}

When the resin was tested following the strong stimulation of histamine as well as insulin, it had a substantial neutralizing effect on gastric acid in both ulcer and non-ulcer patients, when used in sufficient dosage $(3.2 \mathrm{Gm}$.). This effect was closely related to that of aluminum hydroxide (0.6 Gm.) and a modified Sippy powder (0.6 Gm.). Under the conditions employed, the neutralizing effect of each of these antacids varied in different patients and in the same patient at different times. It was felt that this was due in part to deficiencies inherent in the technique employed and in part to the customary variation of gastric secretion. Therefore the relative neutralizing value of these antacids can be interpreted only in a general way. The resin showed a peptic inhibiting effect which in most instances was roughly parallel to the acid neutralization. However, the variability in different subjects and in relation to the other antacids was of about the same order as noted in its effect upon acid.

When studying the gastric and duodenal secretions obtained simultaneously after histamine stimulation we found free acid and pepsin in the duodenal contents regularly in both the non-ulcer and ulcer subjects. Following the administration of the resin there was a fall in the free acid and pep$\sin$ values of the gastric and duodenal secretion and $\mathrm{a}$ rise in the $\mathrm{pH}$ values. However, these changes were not proportionate nor did they parallel each other. In view of the number of factors that can have an influence on gastrointestinal secretion and the unavoidable technical difficulties encountered in this type of study, it is doubtful whether one should expect any greater parallelism in these values.

The use of the absorbable alkalies had been criticised because they produce alkalosis and rebound in the gastric acidity. Hardt and Rivers (12) stated that of a group of 48 patients on alkaline therapy for peptic ulcer, approximately one-third showed toxemia with an increase in the blood urea nitrogen and the carbon dioxide combining power. Palmer (13) feels that this is due to the absorption of sodium bicarbonate, the loss of gastric chloride and/or a combination of both. Alley (14) has shown in dogs that multiple cream feedings and multiple dosage with Sippy powder caused an increase in volume, acidity and pepsin of the gastric juice in comparison to a single large cream feeding. In our study a rebound in gastric acidity occurred in the majority of both ulcer and non-ulcer patients with sodium bicarbonate, whereas this did not occur when the resin or aluminum hydroxide was taken.

Woldman et al. (15) found a progressive rise in gastric acidity and a prolongation of gastric emptying time after multiple doses of protein hydrolysate as recommended for ulcer therapy, but gastric emptying time was not increased signifcantly by aluminum hydroxide. Van Liere and Sleeth (16) added $\mathrm{HCl}$ and sodium bicarbonate in therapeutic doses to test meals given to normal young men and found that the former produced an insignificant delay while the latter definitely reduced evacuation time. Following the recommendations of Babkin (9), we observed the emptying time of the stomach fluoroscopically after giving a radio-opaque meal, and found no significant effect produced by the resin or aluminum hydroxide.

\section{CONCLUSIONS}

1. The anion exchange resin employed in this study is effective in neutralizing acid and inactivating pepsin in the gastric juice of both ulcer and non-ulcer subjects following insulin and repeated dose histamine stimulation. This effect of the resin is comparable to that of a modified Sippy powder and aluminum hydroxide if a sufficiently large dose is employed.

2. The resin caused a substantial reduction in the free acid and pepsin levels and a rise in the $\mathrm{pH}$ value in duodenal contents in both ulcer and nonulcer subjects following repeated dose histamine stimulation.

3. No untoward effects resulted from the dose of resin used.

4. Gastric emptying time is unaffected by the resin.

5. The resin does not cause rebound in gastric acidity.

\section{BIBLIOGRAPHY}

1. Adams, B. A., and Holmes, E. L., Adsorptive properties of synthetic resins. J. Soc. Chem. Ind., 1935, $54,1$. 
2. Segal, H. L., Hodge, H., Watson, J. S., Jr., and Scott, W. J. M., A polyamineformaldehyde resin. Gastroenterology, 1945, 4, 484.

3. Martin, G. J., and Wilkinson, J., The neutralization of gastric acidity with anion exchange resins. Gastroenterology, 1946, 6, 315.

4. Spears, M. M., and Pfeiffer, M. C. J., Anion exchange resin and peptic ulcer pain. Gastroenterology, 1947, 8, 191.

5. Kraemer, M., and Lehman, D. J., Jr., The treatment of peptic ulcer with anion exchange resins. Gastroenterology, 1947, 8, 202.

6. Kraemer, M., and Siegel, L. H., Synthetic resin: a new antacid for treatment of peptic ulcer. Proceedings of 100th Meeting of the A.M.A., Atlantic City, June 13, 1947.

7. Weiss, J., Treatment of gastric and duodenal ulcers with anion exchange resins. Rev. Gastroenterol., $1948,15,826$.

8. Kasdon, S. C., Anion exchange resins in the treatment of heartburn during pregnancy. New England J. Med., 1948, 239, 575.

9. Babkin, B. P., Secretory Mechanisms of the Digestive Glands. Paul B. Hoeber, Inc., New York, 1944.
10. Rivers, A. B., Osterberg, A. E., and Vanzant, F. R., The double histamine test as an aid in the study of gastric secretory function. Am. J. Digest. Dis. \& Nutrition, 1936, 3, 12.

11. Friedman, M. H. F., A simplified procedure for the determination of pepsin and trypsin concentrations in digestive juices. Gastroenterology, 1947, 8, 526.

12. Hardt, L. L., and Rivers, A. B., Toxic manifestations following alkaline treatment of peptic ulcer. Arch. Int. Med., 1923, 31, 171.

13. Palmer, W. L., Alkalosis in antacid therapy. Gastroenterology, 1943, 1, 892.

14. Alley, A.,. Effects on gastric secretion in dogs of various food-substances employed in treatment of gastric ulcer. Am. J. Digest. Dis. \& Nutrition, 1934, 1, 555.

15. Woldman, E. E., Fishman, D., Knowlton, R. S., Rousuck, A. A., and Stoner, W. C., Evaluation of protein hydrolysate therapy of peptic ulcer. J. A. M. A., 1948, 137, 1289.

16. Van Liere, E. J., and Sleeth, C. K., The emptying time of the normal human stomach as influenced by acid and alkali with a review of the literature. Am. J. Digest. Dis. \& Nutrition, 1940, 7, 118. 